\title{
DESAFIOS NA ELABORAÇÃO DE SITUAÇÕES DE APRENDIZAGEM PARA CURSOS EAD
}

\author{
SALVADOR/BA AGOSTO/2018 \\ Regiani Coser Cravo - SENAI - regicoser@outlook.com \\ Rafael Barretto Arruda - SENAI - rbarruda@hotmail.com \\ Tipo: Relato de Experiência Inovadora (EI) \\ Categoria: Métodos e Tecnologias \\ Setor Educacional: EDUCAÇÃO MÉDIA E TECNOLÓGICA
}

\begin{abstract}
RESUMO
O propósito deste estudo é apresentar um relato de experiência sobre os desafios encontrados na construção de situação de aprendizagem (SA) nos cursos de educação a distância (EAD) desenvolvidos pela Unidade de Inovação e Tecnologias Educacionais do [blind review]. Essa construção é baseada na Metodologia [blind review] de Educação Profissional (MSEP), que direciona para uma formação por competência, oportunizando ao aluno um papel de destaque no processo educacional.
\end{abstract}

Palavras-chave: desafios; competência; metodologia EAD 


\section{1- INTRODUÇÃO}

A globalização, as mudanças no mundo do trabalho oriundas principalmente devido aos avanços tecnológicos, têm modificado a dinâmica da vida das pessoas. Na busca da manutenção de seus empregos, ou de melhores oportunidades no mercado de trabalho, a realização de cursos para o aperfeiçoamento profissional tem se tornado crescente.

Conciliar o tempo para trabalho, estudo, família e lazer não é uma tarefa simples. Desta forma, a qualificação por meio de Educação a Distância (EAD) tem se tornado uma solução eficaz, uma vez que possibilita a flexibilidade de horários para estudo, permitindo que as pessoas possam organizar em suas agendas o tempo e o momento de dedicação às atividades educacionais.

Apesar das facilidades, os cursos da modalidade a distância, para que proporcionem as expectativas e objetivos esperados, requerem disciplina e capacidade de autodesenvolvimento dos alunos. Outrossim, é de fundamental importância que o programa esteja estruturado metodologicamente de forma aderente à modalidade a distância, isto é, tenha a organização curricular e os conteúdos preparados sob medida para as pessoas que irão estudar fora do ambiente tradicional de sala de aula, por meio do auxílio de tecnologias educacionais e com apoio de tutores em momentos específicos.

Para atender ao público-alvo dos cursos a distância, o [blind review], em parceria com o [blind review], desenvolve cursos na modalidade a distância para o Programa [blind review] de Educação a Distância (PSEAD) baseados em situações de aprendizagem, que são ofertados pela referida Instituição. Para isso, conta com uma equipe multidisciplinar de profissionais de educação, comunicação, tecnologia e com a atuação de conteudistas de áreas técnicas específicas para a elaboração de SA. O referido conteudista é um profissional que apresenta competências reconhecidas nas áreas de conhecimento dos cursos do [blind review]. Ele é quem constrói o conteúdo didático para o ambiente virtual de aprendizagem a partir da proposta apresentada no plano de curso.

Ademais, considerando a necessidade de um ambiente virtual de aprendizagem que contenha informações de fácil interpretação e entendimento, o processo de escrita de conteúdos técnicos torna-se desafiador. Isso porque, escrever vai além de depositar as palavras em determinado local, e sim, articular conceitos e ideias de modo que ajudem o aluno a criar significado e desenvolver competências.

O objetivo desse relato é apresentar os desafios encontrados pelo conteudista do [blind 
review] ao elaborar a situação de aprendizagem, de modo que oriente demais especialistas na construção de SA.

\section{2- ENSINO POR COMPETÊNCIA}

O início do século XX foi marcado pela implantação das teorias de Frederick W. Taylor no sistema de produção da indústria automotiva. Este método produtivo, também chamado de taylorismo-fordismo, caracterizou-se pela subdivisão do trabalho em tarefas específicas, que deveriam ser atribuídas a trabalhadores, permitindo a sua especialização e máxima eficiência. Baixa autonomia, foco nos tempos de movimentos e rotina eram aspectos que predominavam neste modelo de produção, onde a força pensante era dissociada da força executante.

Dentro deste contexto histórico, moldou-se o processo de educação profissional, que com o objetivo de atender à demanda de mão de obra, traçava estratégias e metodologias para o desenvolvimento de conhecimentos limitados às rotinas de trabalho. O indivíduo era formado com foco na técnica, de modo que pudesse desenvolver o ofício repetidas vezes com o máximo de produtividade. Este modelo de educação conteudista era caracterizado pelo ensino frontal, pela transmissão de informações e o desenvolvimento de habilidades manipulativas, ou seja, o passo a passo necessário para se executar uma tarefa, atendendo aos parâmetros desejados e com o mínimo de tempo.

O desenvolvimento tecnológico crescente, principalmente na segunda metade do século $X X$, traçou novas rotas nos sistemas de produção. O toyotismo, criado no Japão, trouxe uma nova perspectiva no mundo do trabalho. A atuação dos profissionais foi ampliada de um conceito predominantemente mecanizado, para execução de atividades variadas e complexas, além disso, a interação e o trabalho em equipe também são marcantes neste novo modelo. O profissional passa a ser valorizado e sua capacidade criativa é entendida como um recurso estratégico para o desenvolvimento das organizações, que buscam crescimento no competitivo mercado global.

Diante desta realidade, o perfil da mão de obra requerido pelas empresas também passou por transformações. A solução de problemas complexos, a criatividade e o trabalho em equipe são características necessárias para o desenvolvimento das novas atividades presentes no ambiente laboral. Estas mudanças impulsionaram a evolução do processo de educação, para atender a esta nova realidade, e em resposta aos desafios emergentes no segmento industrial, o [blind review] promoveu uma série de estudos técnicos e pedagógicos que culminaram no desenvolvimento da Metodologia [blind 
review] de Educação Profissional.

\section{1- METODOLOGIA [blind review] DE EDUCAÇÃO PROFISSIONAL}

A MSEP busca promover a formação de profissionais, que além de dominar a área específica de atuação, tenham capacidades como habilidades de comunicação, trabalho em equipe, criatividade e relacionamento interpessoal, de modo que estas características, integradas, contribuam para a solução de problemas e desenvolvimento de atividades de forma inovadora e eficiente.

A figura seguinte exemplifica a MSEP, que se estrutura por meio de três pilares: Perfil Profissional, Desenho Curricular e Prática Docente. No primeiro, é trazido o perfil do profissional, suas características e competências necessárias para o desenvolvimento das atividades. A partir da construção do perfil, é possível desenhar quais unidades curriculares são necessárias para que o discente desenvolva as competências já definidas. $O$ desenho das unidades curriculares contempla os fundamentos técnicos e científicos, as capacidades técnicas, organizativas, sociais e metodológicas. Desta forma, ao ministrar uma aula, a atenção do docente não estará somente no conteúdo a ser ministrado, e sim onde se quer chegar com este conteúdo, ou seja, qual competência será desenvolvida no aluno. E, por fim, a prática docente, que é pautada nas estratégias de ensino utilizadas para que os conteúdos sejam transformados em competências no indivíduo por meio de situações de aprendizagem.

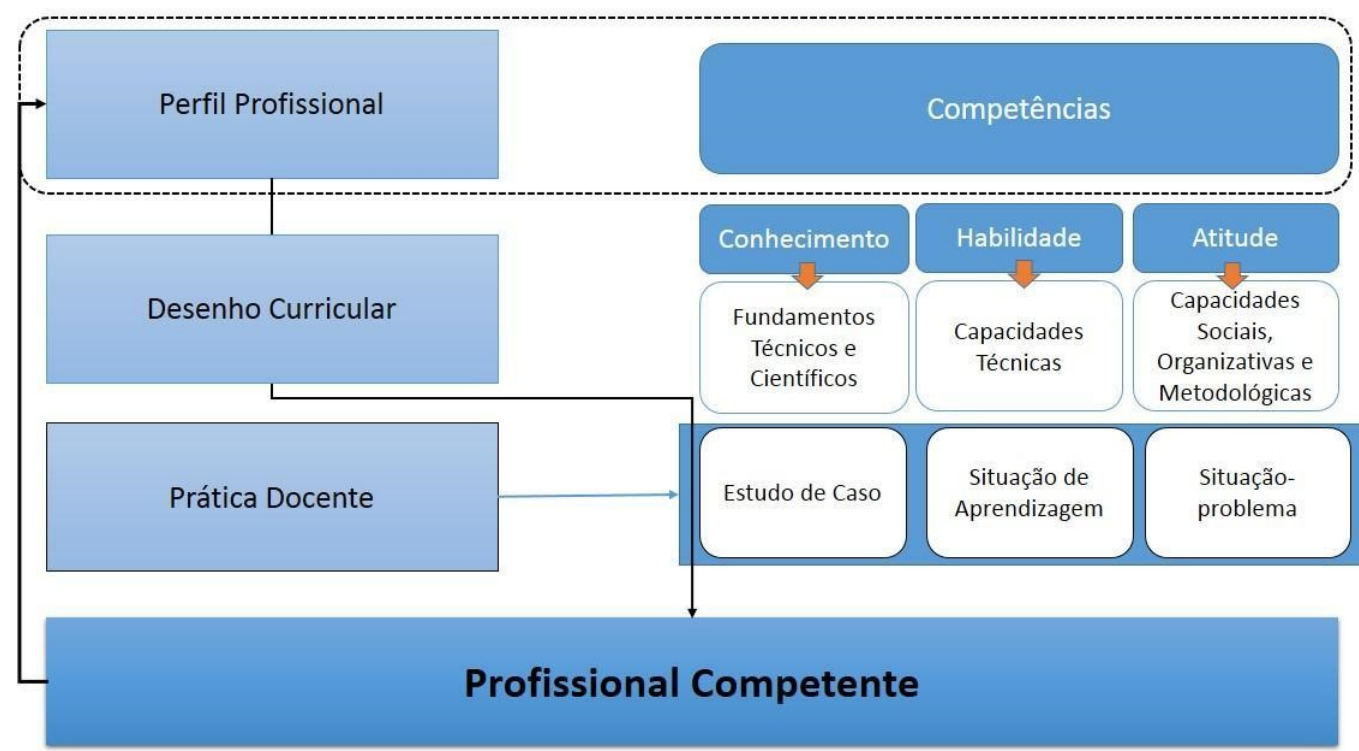

Figura 1. Fluxograma da MSEP 
Fonte: Elaborado pelo autor.

Esta metodologia promove uma formação baseada em competências. Segundo Perrenoud (1999, p. 30): "Competência é a faculdade de mobilizar um conjunto de recursos cognitivos (saberes, capacidades, informações, etc.) para solucionar com pertinência e eficácia uma série de situações".

Enquanto que no modelo tradicional de ensino o principal caminho trilhado é pautado na informação e transmissão de conteúdo tendo o docente como protagonista; a formação por competência tem como mola propulsora a promoção do aluno para o centro do processo educacional, através de situações de aprendizagem que o motive a pensar, agir, pesquisar, compreender fundamentos e mobilizar conhecimentos para a solução de problemas que possibilitarão o desenvolvimento dessas competências.

\section{2- SITUAÇÃO DE APRENDIZAGEM}

A situação de aprendizagem, de acordo com a Metodologia [blind review] de Educação Profissional, é definida como:

[...] um conjunto de ações que planejadas pedagogicamente favorecem aprendizagens significativas, por meio da utilização de Estratégias de Aprendizagem Desafiadoras (situação-problema, estudo de casos, projeto e pesquisa aplicada) e diferentes estratégias de ensino (exposição dialogada ou mediada, demonstração, estudo dirigido, visitas técnicas, entre outras). (SENAl, 2013, p. 121).

Desta forma, a estratégia pedagógica baseia-se em inserir o aluno em uma situação similar à encontrada no ambiente de trabalho e provocar a mobilização de conceitos, procedimentos, técnicas e fundamentos estudados previamente, de modo que sejam aplicados na resolução de problemas aderentes à formação pretendida. À medida que o aluno soluciona as etapas de uma situação de aprendizagem, desenvolve capacidades e competências conforme objetivos das unidades curriculares.

O processo de construção de uma situação de aprendizagem requer pessoas com habilidades de escrita e que tenham uma visão holística do sistema metodológico da educação a distância do [blind review]. Assim, este processo requer uma análise detalhada do plano de curso e da unidade curricular em questão, para que se possa identificar as competências, capacidades técnicas, sociais, organizativas e metodológicas, que o aluno precisa desenvolver para atender às expectativas do mercado de trabalho no que tange às funções realizadas.

Esta análise é a base para a elaboração de uma situação de aprendizagem, uma vez 
que permite identificar o alvo do processo educacional, ou seja, onde se quer chegar, entendendo que todo processo construtivo deve contemplar a inserção de conteúdos e a utilização de estratégias que viabilizem o alcance desse objetivo.

A estrutura da SA compreende, principalmente, o contexto, os conceitos essenciais e as atividades. No contexto, constrói-se uma problemática que norteará o aluno durante 0 estudo e que contemple, de modo contextualizado, situações e vivências do mercado de trabalho. Os conceitos essenciais são selecionados pelo especialista da unidade curricular, pois subsidiam o aluno para adquirir os conhecimentos teóricos necessários para a solução das atividades propostas. Na etapa final, o aluno realiza a atividade que está atrelada às capacidades descritas no plano de ensino.

Por fim, ressalta-se que o estudo da situação de aprendizagem não se limita aos materiais on-line, uma vez que contempla estratégias de ensino que são realizadas no ambiente virtual e em encontros presenciais. Desse modo, a SA se apresenta como fio condutor de todo o processo de aprendizagem.

\section{3- DESAFIOS NA CONSTRUÇÃO DE SA NA MODALIDADE EAD}

O processo de construção de situação de aprendizagem na modalidade a distância envolve alguns desafios para o conteudista, que são:

- O entendimento da Metodologia [blind review] de Educação Profissional e da Metodologia de Educação a Distância

Referente ao entendimento da MSEP, é importante entender os caminhos propostos por essa metodologia para se atingir os objetivos do processo educacional. Ao contrário o ensino clássico, que coloca o professor no centro do processo de ensino e aprendizado, tornando relevante o conceito de transmissão de informações e tendo o aluno como um elemento passivo, na MSEP o docente é um mediador deste processo e o aluno protagoniza as ações à medida que participa de dinâmicas, desafios e situaçõesproblemas. O foco deixa de ser o conteúdo e passa a ser as competências que precisam ser desenvolvidas pelo aluno.

Isto muda a concepção do que deve ser escrito pelo conteudista na SA. A informação não pode estar solta e sim atrelada a uma ou mais competências necessárias para o desenvolvimento das atividades profissionais.

A EAD é "a modalidade educacional na qual alunos e professores estão separados, 
física ou temporalmente e, por isso, faz-se necessária a utilização de meios e tecnologias de informação e comunicação." (O QUE..., [20--]). Assim, considerando a Metodologia de Educação a Distância, a separação entre docente e aluno requer um tipo de abordagem diferente no que tange à disposição de conteúdos técnicos. A linguagem deve ser clara, objetiva e coerente, de modo que facilite a compreensão dos conceitos e fundamentos estudados, que servirão como instrumento para que o aluno possa solucionar os desafios propostos.

A seleção dos recursos tecnológicos é outro aspecto importante na Metodologia de Educação a Distância. Faz-se necessário identificar quais recursos são aderentes ao escopo técnico do curso e ao perfil do aluno. Esta sincronização entre recurso e utilitário, quando realizada de forma adequada, oportunizará um aprendizado dinâmico e rico em conhecimento.

- A interpretação do plano de curso e a construção do plano integrado de uma situação de aprendizagem

O plano de curso, de acordo com glossário da educação profissional e tecnológica do [blind review], é definido como:

[...] documento elaborado pela equipe técnico-pedagógica com decisões relacionadas a justificativa e objetivos, requisitos de acesso, perfil profissional de conclusão, organização curricular, critérios de aproveitamento de estudos e competências, critérios de avaliação, instalações e equipamentos, pessoal docente e técnico, e certificados e diplomas. (SENAI, 2009).

O plano de curso é a base para a elaboração de uma situação de aprendizagem. Para escrever o conteúdo e propor um desafio é necessário saber qual o objetivo do curso e o papel da unidade curricular dentro deste curso. Além disso, atendendo aos pressupostos da MSEP, é importante saber quais competências técnicas, organizativas, sociais e metodológicas espera-se que o aluno desenvolva ao término do estudo dos conteúdos e objetos de conhecimento que serão aplicados na solução dos desafios propostos.

Pautado nessas premissas, é possível construir o plano integrado de uma disciplina. Este plano combina os requisitos apresentados no desenho curricular da disciplina com os conteúdos, contextos e atividades que compõem a situação de aprendizagem. Neste documento é possível ter uma visão macro de como se planeja desenvolver as competências do aluno, ou seja, compreende todas etapas a serem percorridas na execução da unidade curricular.

- A estruturação do desafio e a seleção dos conceitos essenciais para o alcance 
dos objetivos da unidade curricular

$\mathrm{Na}$ estruturação do desafio é necessário criar um contexto e um problema, similar ao mundo do trabalho, selecionado sob medida para possibilitar ao aluno 0 desenvolvimento das competências especificadas na unidade curricular. O conteudista, de posse destes objetivos, deve utilizar a sua experiência profissional para propor a atividade chave. Isto é possível por meio da análise das principais tarefas presentes no cotidiano profissional e que contemplem a mobilização dos conhecimentos e o desenvolvimento das competências propostas na disciplina. Ou seja, é necessário criar um problema considerando que, para sua solução, o aluno deverá estudar e compreender conceitos e fundamentos técnicos e, a partir disso, aplicar estes conhecimentos realizando a atividade.

A gamificação e trabalhos em equipe podem ser adotados como estratégias para dinamizar e estimular os alunos na solução dos desafios. Permitem também o desenvolvimento de outras habilidades como comunicação e relacionamento interpessoal.

A seleção e escrita dos conceitos essenciais representam uma importante etapa na construção de uma situação de aprendizagem, uma vez que a presença de longos textos pode tornar o estudo "entediante", contribuindo para desestimular o aluno. Desta forma, a utilização de vídeos, imagens, gráficos, objetos de aprendizagem e animações devem não apenas complementar, mas demonstrar o conteúdo de diversas formas, aproveitando o potencial de cada mídia, contribuindo para uma aprendizagem mais dinâmica e interessante, de modo que desperte o interesse e prenda a atenção dos discentes.

\section{3- CONSIDERAÇÕES FINAIS}

Com base nos argumentos deste relato, e das experiências não apenas de conteudista, mas também docente e mediador na educação a distância, é possível constatar que o conteúdo não é um fim e sim um meio para o alcance dos objetivos. A proposta da Metodologia [blind review] de Educação Profissional, aplicada por meio de situações de aprendizagem, permite que o aluno vivencie de forma prática os desafios do mundo do trabalho e, dentro deste contexto, identifique as necessidades de fundamentações, técnicas e conhecimentos necessários para solução dos diversos problemas inerentes à profissão escolhida.

Isto proporciona ao aluno uma aprendizagem mais significativa, que é desafiada pela 
situação-problema a compreender os conteúdos de forma que possa usá-los para resolver determinada atividade. Nesta proposta é possível identificar que o aluno se torna protagonista do próprio aprendizado, e que ao longo do caminho percorrido e das atividades realizadas, desenvolve as capacidades e competências esperadas.

Especialmente nos cursos de educação a distância, que em função das características inerentes à sua operacionalização, a exemplo da separação física tutor-aluno, necessidade de autodisciplina e gerenciamento de tempo, requer um processo de ensino atrativo, dinâmico e lúdico, tendo a situação de aprendizagem como um conjunto de ações que norteará o aluno no seu desenvolvimento.

\section{Referências}

O QUE é educação a distância?. [20--]. Disponível em: $<$ http://portal.mec.gov.br/escola-de-gestores-da-educacao-basica/355-perguntas-frequen $\underline{\mathrm{t}}$

$\underline{\mathrm{e}}$

s-911936531/educacao-a-distancia-1651636927/12823-o-que-e-educacao-a-distancia $>$. Acesso em: 20 jul. 2018.

PERRENOUD, Philippe. Avaliação: da excelência à regulação das aprendizagens entre duas lógicas. Porto Alegre: Artmed, 1999.

SERVIÇO NACIONAL DE APRENDIZAGEM INDUSTRIAL. Departamento Nacional. Metodologia SENAI de educação profissional. Brasília: SENAI/DN, 2013.

SERVIÇO NACIONAL DE APRENDIZAGEM INDUSTRIAL. Glossário da educação profissional e tecnológica do SENAl. Brasília: CNI, 2009. Disponível em: $<$ http://www.senai.br/glossario/>. Acesso em: 02 jul. 2018. 